\title{
Long-term outcomes of patients with diabetes receiving bilateral internal thoracic artery grafts
}

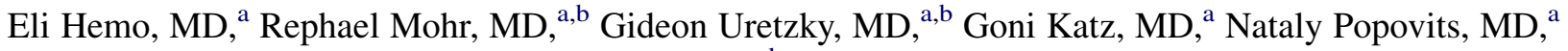 \\ Dmitry Pevni, MD, ${ }^{\mathrm{a}, \mathrm{c}}$ and Benjamin Medalion, $\mathrm{MD}^{\mathrm{b}, \mathrm{c}}$
}

\begin{abstract}
Objectives: Bilateral internal thoracic artery (BITA) grafting in patients with diabetes are controversial because of increased risk of sternal infection. On the other hand, patients with diabetes may benefit from BITA grafts because of the associated improved survival. This study evaluated factors affecting early and long-term outcomes for better selection of patients with diabetes for BITA grafts.
\end{abstract}

\begin{abstract}
Methods: Between 1996 and 2006, 69 patients with insulin-treated diabetes and 732 with orally treated diabetes received isolated skeletonized BITA grafts. Of these patients, 338 were younger than 65 years, 322 were between 65 and 74 years old, and 141 were 75 years or older.

Results: Operative mortality was lower than logistic EuroSCORE-calculated mortality $(2.9 \%$ vs $7 \%, P<.001)$. Predictors of increased mortality were critical preoperative state $(P<.001)$ and age $(P=.008)$. There were 30 cases of sternal infection $(3.7 \%)$; predictors were reoperation $(P<.001)$, peripheral vascular disease $(P=.009)$, obesity $(P=.012)$, chronic lung disease $(P=.009)$, and female sex $(P=.020)$. Mean follow-up was $8.4 \pm 4$ years. Kaplan-Meier 10 -year survivals were $75 \%, 59 \%$, and $39 \%$ for patients younger than 65,65 to 74 , and at least 75 years, respectively $(P<.001)$. They were better than corresponding Charlson comorbidity index-predicted survivals $(36 \%, 10 \%$, and $3 \%$, respectively; $P<.001)$. Predictors of decreased survival were age $(P<.001)$, congestive heart failure $(P<.001)$, and peripheral vascular disease $(P<.001)$. Off-pump surgery was independently associated with better long-term survival $(P=.003)$.
\end{abstract}

Conclusions: BITA grafts are safe in patients with diabetes. Favorable short- and long-term outcomes outweigh increased sternal infection risk. (J Thorac Cardiovasc Surg 2013;146:586-92)

Ischemic heart disease is the leading cause of death in patients with diabetes mellitus. ${ }^{1}$ Patients with diabetes have a tendency toward development of multivessel disease, and their prognosis is worse than that of patients without diabetes. More and more patients with diabetes are being referred for coronary artery bypass grafting (CABG) or for angioplasty for revascularization of the coronary system, ${ }^{2}$ which makes them a large proportion of the patients undergoing these procedures. ${ }^{3}$

Surgical revascularization of the left anterior descending artery with the internal thoracic artery (ITA) is still the only proven method of improving event-free survival in patients with multivessel disease. ${ }^{4,5}$ Long-term follow-up of the Bypass Angioplasty Revascularization Investigation study showed that in patients diabetes with multivessel disease,

From the Departments of Cardiothoracic Surgery, ${ }^{\mathrm{a}}$ Tel Aviv Sourasky Medical Center, Tel Aviv, Israel; the Department of Cardiothoracic Surgery, ${ }^{\mathrm{b}}$ Sackler School of Medicine, Tel Aviv University, Tel Aviv, Israel; and the Department of Cardiothoracic Surgery, ${ }^{\mathrm{c}}$ Beilinson Medical Center, Petah Tikva, Israel.

Disclosures: Authors have nothing to disclose with regard to commercial support.

Received for publication Jan 23, 2012; revisions received March 22, 2012; accepted for publication April 6, 2012; available ahead of print Aug 23, 2012.

Address for reprints: Rephael Mohr, MD, Department of Cardiothoracic Surgery, Tel Aviv Sourasky Medical Center, 6 Weizman St, Tel Aviv 64239, Israel (E-mail: marion@tasmc.health.gov.il)

0022-5223/\$36.00

Copyright (c) 2013 by The American Association for Thoracic Surgery

http://dx.doi.org/10.1016/j.jtcvs.2012.04.024
CABG was associated with significantly lower rates of sudden death and myocardial infarction-related death ${ }^{6}$ than was angioplasty. Left anterior descending revascularization in that study was an independent predictor of long-term survival.

Similar findings were reported later in the Arterial Revascularization Therapy study. ${ }^{7}$ In that study, the 3-year survival of patients with diabetes undergoing CABG was higher than that of patients with diabetes undergoing coronary angioplasty with bare-metal stents.

Bilateral ITA (BITA) grafting is associated with improved survival relative to $\mathrm{CABG}$ with single ITA grafts and saphenous vein grafts (SVGs). ${ }^{7}$ In addition to improved survival, patients with BITA had better event-free survival and reduced occurrence of reinterventions. ${ }^{7} \mathrm{De}-$ spite the improved long-term outcomes in patients without diabetes, the application of this technique in those with diabetes remains controversial because of the increased risk of sternal infection and subsequent lethal mediastinitis as a result of sternal devascularization. ${ }^{8}$ Collateral circulation to the sternum can be partially preserved if the conduit is harvested as a skeletonized conduit. ${ }^{9}$ Dividing the collateral branches with hemostatic clips and scissors enables maintenance of collateral perfusion from the intercostal or the muscular branches, which are usually destroyed by the use of the cautery and the dissection of the conduit as a pedicle. 


$$
\begin{array}{ll}
\text { Abbreviations and Acronyms } \\
\text { BITA }=\text { bilateral internal thoracic artery } \\
\text { CABG }=\text { coronary artery bypass grafting } \\
\text { CCI }=\text { Charlson comorbidity index } \\
\text { CI }=\text { confidence interval } \\
\text { COPD } & \text { chronic obstructive pulmonary disease } \\
\text { HR } & =\text { hazard ratio } \\
\text { ITA } & =\text { internal thoracic artery } \\
\text { OPCAB } & \text { off-pump coronary artery bypass } \\
& \text { grafting } \\
\text { OR } & =\text { odds ratio } \\
\text { PVD } & =\text { peripheral vascular disease } \\
\text { RCA } & \text { right coronary artery } \\
\text { SVG } & =\text { saphenous vein graft }
\end{array}
$$

The lack of complete sternal devascularization in the first days after the operation can also form the basis for improved sternal wound healing in patients with diabetes ${ }^{9}$; in our experience, however, occurrence of sternal wound infection was still higher in patients with diabetes than in those without, and diabetes has been found to be a significant predictor of sternal wound infection in multivariable logistic regression analysis. ${ }^{10}$ Despite the increased risk of sternal complications, patients with diabetes may still benefit from BITA grafting because of their accelerated atherosclerosis and the increased propensity toward SVG failure. . $^{41}$

The purpose of this study was to evaluate early and longterm outcomes of skeletonized BITA grafting in patients with diabetes to determine whether potential survival benefit outweighs the increased risk of sternal infection. We also wished to evaluate preoperative and operative factors affecting early and long-term outcomes to improve selection of patients with diabetes to receive BITA grafts.

\section{MATERIALS AND METHODS}

From January 1996 to December 2006, a total of 801 consecutive patients with diabetes underwent myocardial revascularization with BITAs that were dissected as skeletonized arteries. ${ }^{9}$ They comprised $30.6 \%$ of the 2615 isolated BITA grafting procedures performed in the Tel Aviv Sourasky Medical Center during this time. Preoperative and operative patient data were collected from the hospital medical records with institutional review board approval. To evaluate the effects of age on early and long-term outcomes, patients were stratified into 3 age groups: 64 years old or younger, between 65 and 74 years old, and 75 years or older. To evaluate the learning curve effect, patients were stratified according to their operative date into 2 groups: early (1996-1999) and late (2000-2006).

Expected operative mortality was calculated with the logistic EuroSCORE $^{12}$ and compared with the observed early mortality. Expected midterm and long-term mortalities without operation were calculated with the Charlson comorbidity index $(\mathrm{CCI})^{13}$ and compared with the expected survival of the Israeli population of the same age and sex distribution ${ }^{14}$ and with the Kaplan-Meier actuarial survival. Follow-up was obtained with the Israeli National Registry database and a telephone questionnaire.

\section{Surgical Techniques}

Operations were performed with standard cardiopulmonary bypass or as off-pump CABG (OPCAB). Myocardial preservation during cardiopulmonary bypass involved intermittent, antegrade or retrograde blood cardioplegia $\left(30^{\circ} \mathrm{C}-32^{\circ} \mathrm{C}\right)$. Coronary stabilization during $\mathrm{OPCAB}$ was facilitated with CTS stabilizers (Guidant, Indianapolis, Ind) or the Octopus system (Medtronic, Minneapolis, Minn). ITAs were mobilized from the chest wall as skeletonized vessels. ${ }^{9,15}$ In most cases, BITAs were used to graft the left coronary system, the myocardial territory supplied by the left anterior descending and circumflex arteries. Two arrangements were implemented: a free right ITA attached proximally end to side on the left ITA in a T-graft configuration (composite T-graft) and an in situ BITA with an anteaortic crossover right ITA. The choice of configuration was determined by previously detailed technical considerations. ${ }^{15}$ The type of conduit selected for right coronary artery (RCA) grafting was not related to the configuration of the ITAs. Our strategy was to use right ITAs, right gastroepiploic arteries, and radial arteries as grafts to the RCA branches only in the presence of a significant stenosis $(>80 \%) .{ }^{16}$ When the RCA system was unsuitable for arterial grafting, such as in cases with a potential for high competitive flow in the RCA, we selected SVG as the conduit for revascularization of the RCA.

To decrease the risk of spasm of the arterial grafts, all patients were treated with a high-dose intravenous infusion of isosorbide dinitrate (Isoket; $4-20 \mathrm{mg} / \mathrm{h}$ ) during the first 48 postoperative hours. Calcium-channel blockers (diltiazem hydrochloride [INN diltiazem]; $90-180 \mathrm{mg} / \mathrm{d}$ orally) were given to patients operated on using right gastroepiploic artery or radial artery from the second postoperative day for at least 3 months. ${ }^{15}$

\section{Definition of Terms and Data Collection}

Patient data were analyzed according to American College of Cardiology and American Heart Association Clinical Data Standards. ${ }^{17}$

Chronic renal failure was diagnosed if the creatinine level exceeded 1.8 $\mathrm{mg} / \mathrm{dL}$. Peripheral vascular disease (PVD) included all symptomatic and asymptomatic extracoronary arteriopathy. Cerebrovascular disease included history of any previous cerebrovascular event, with or without permanent neurologic damage.

Our definition of an emergency operation was based on the Society of Thoracic Surgeons guidelines and included patients operated on within 24 hours of cardiac catheterization, with ongoing angina, acute evolving myocardial infarction, pulmonary edema, or cardiogenic shock. ${ }^{18} \mathrm{~Pa}-$ tients who needed emergency surgery and were not stabilized after intra-aortic balloon counterpulsation were usually operated on with a single ITA combined with SVGs and therefore were not included. A perioperative myocardial infarction was defined by the appearance of new $\mathrm{Q}$ waves in the electrocardiogram associated with elevated levels of creatine kinase $\mathrm{MB}$ fraction $(>50 \mathrm{mU} / \mathrm{mL})$. A cerebrovascular accident was defined as a new permanent neurologic deficit with computed tomographic evidence of cerebral infarction. Deep sternal infection was defined as the sum of deep infection and late dehiscence requiring sternectomy.

\section{Statistical Analysis}

Data are expressed as the mean $\pm \mathrm{SD}$ or as a proportion. The $\chi^{2}$ test and 2 -sample $t$ tests were used to compare discrete and continuous variables, respectively. Multivariable logistic regression analysis was used to predict early mortality and early morbidity events by various risk factors. The odds ratios (ORs) with $95 \%$ confidence intervals (CIs) are given. Postoperative survivals of each age group are expressed by the Kaplan-Meier method, and survival curves were compared with the log-rank test. The Cox proportional hazard model was used to evaluate the influence of preoperative variables and operative data on late and overall mortalities. A Cox model was used to compare adjusted survivals between the various age groups after controlling for differences between groups in preoperative and operative 
characteristics. Results of Cox analysis are expressed as hazard ratios (HRs) with $95 \%$ CIs.

To present the expected annual survival of the general population on the basis of our sample of patients, we used the 2005 through 2009 complete life tables published by the Israeli National Central Bureau of Statistics ${ }^{14}$ to calculate the annual survival for each patient according to age and sex out to 15 years. In addition, we used the CCI formulation to calculate the expected 10-year survivals of our patients assuming no surgery was performed. The $\mathrm{CCI}$ formulation estimates survival of people according their age and certain comorbidities. It has been validated for 10 -year survival. ${ }^{13}$ For presentation purpose only, we extended the CCI formulation principle to calculate the estimated annual survival of each patient according to age and CCI out to 15 years. The CCI formulation uses a 10-year survival of a 40-year-old person with no comorbidities $(98 \%)$ ) as the baseline survival for its calculations. We used the relative annual survival of a 40 -year-old person taken from the Israeli complete life tables ${ }^{14}$ as the baseline survival to calculate the annual estimated survival of each patient without surgery. Because the CCI formulation has been validated for 10-year survival only, we performed formal statistical comparison of survival between the expected general population survival, observed actuarial survival, and estimated survival of the patients if no operation had been performed only at 10 years with a 1 -sample $t$ test.

Statistical analysis was performed with SPSS for Windows version 19 (IBM Corporation, Armonk, NY).

\section{RESULTS}

The patients' preoperative characteristics and their relationships with early postoperative mortality are presented in Table 1.

The mean number of grafts per patient was 3.04. The actual early mortality was lower than the logistic EuroSCORE-calculated mortality $(2.9 \%$ vs $7 \% ; P<.001)$.

Multivariable logistic regression revealed critical preoperative state (OR, 9.734; 95\% CI, 3.698-25.623) and increased age (OR, 1.078; 95\% CI, 1.019-1.132) to be independently associated with increased operative mortality. Patients undergoing OPCAB procedures had decreased operative mortality (Table 1) and significantly lower Coxadjusted mortality (OR, 0.263; 95\% CI, 0.071-0.976; $P=.046)$.

Early postoperative morbidity (Table 2 ) included sternal infection $(3.7 \%)$, cerebrovascular accident $(2.1 \%)$, and perioperative myocardial infarction $(0.4 \%)$. Multivariable correlates of sternal infection were reoperation (OR, 12.432; 95\% CI, 3.388-45.64; $P<.001)$, chronic

TABLE 1. Patient characteristics and early mortality $(\mathbf{N}=\mathbf{2 3})$

\begin{tabular}{|c|c|c|c|c|c|c|c|}
\hline \multirow[b]{2}{*}{ Risk factor } & \multicolumn{2}{|c|}{ Prevalence of risk factor } & \multicolumn{2}{|c|}{ Mortality with risk factor } & \multicolumn{2}{|c|}{ Mortality without risk factor } & \multirow[b]{2}{*}{$P$ value } \\
\hline & $\mathbf{N}$ & $\%$ & $\mathbf{N}$ & $\%$ & $\mathbf{N}$ & $\%$ & \\
\hline Age $<65$ y & 338 & 42.2 & 3 & 0.9 & 20 & 4.1 & .013 \\
\hline Age $65-74$ y & 322 & 40.2 & 15 & 4.7 & 8 & 1.7 & .013 \\
\hline Age $\geq 75$ y & 141 & 17.6 & 5 & 3.5 & 18 & 2.7 & .013 \\
\hline Female & 200 & 25 & 8 & 4 & 15 & 2.5 & .192 \\
\hline Type 1 diabetes & 69 & 8.6 & 2 & 2.9 & 21 & 2.9 & .605 \\
\hline COPD & 39 & 4.9 & 4 & 10.3 & 19 & 2.5 & .022 \\
\hline Congestive heart failure & 205 & 25.6 & 12 & 5.9 & 11 & 1.8 & .005 \\
\hline Chronic renal failure & 68 & 8.5 & 5 & 7.4 & 18 & 2.5 & .038 \\
\hline PVD & 202 & 25.2 & 11 & 5.4 & 12 & 2.0 & .011 \\
\hline RCA revascularization & 489 & 61 & 14 & 2.9 & 9 & 2.9 & $>.999$ \\
\hline Hypertension & 508 & 63 & 14 & 2.8 & 9 & 3.1 & .477 \\
\hline Hyperlipidemia & 495 & 62 & 12 & 2.4 & 11 & 3.6 & .335 \\
\hline Acute myocardial infarction $(\leq 1 \mathrm{wk})$ & 140 & 17.4 & 4 & 2.9 & 19 & 2.9 & .626 \\
\hline Intra-aortic balloon pump & 41 & 5.1 & 5 & 12.2 & 18 & 2.4 & .005 \\
\hline Old myocardial infarction ( $>1 \mathrm{wk})$ & 334 & 41.7 & 14 & 4.2 & 9 & 1.9 & .058 \\
\hline Unstable angina pectoris & 454 & 56.7 & 12 & 2.6 & 11 & 3.2 & .658 \\
\hline Left main disease & 209 & 26 & 7 & 3.3 & 16 & 2.7 & .871 \\
\hline Ejection fraction $\leq 30 \%$ & 60 & 7.5 & 2 & 3.3 & 21 & 2.8 & .526 \\
\hline Critical preoperative state* & 59 & 7.4 & 8 & 13.6 & 15 & 2.0 & $<.001$ \\
\hline Emergency operation & 71 & 8.9 & 4 & 5.6 & 19 & 2.6 & .144 \\
\hline Reoperation & 18 & 2.2 & 1 & 5.6 & 21 & 2.8 & .411 \\
\hline Triple-vessel disease & 644 & 80.4 & 23 & 3.6 & 0 & 0 & .016 \\
\hline Composite $\mathrm{T}$ graft & 454 & 56.7 & 13 & 2.9 & 10 & 2.9 & $>.999$ \\
\hline OPCAB & 232 & 29 & 3 & 1.3 & 20 & 3.5 & .088 \\
\hline Bypass grafts $(\geq 3)$ & 581 & 72.5 & 15 & 2.6 & 8 & 3.6 & .425 \\
\hline Obesity (BMI $\geq 30 \mathrm{~kg} / \mathrm{m}^{2}$ ) & 122 & 15.2 & 2 & 1.6 & 21 & 3.1 & .318 \\
\hline Early period (1996-1999) & 320 & 40 & 13 & 4.1 & 10 & 2.1 & .078 \\
\hline
\end{tabular}

$B M I$, Body mass index; $C O P D$, chronic obstructive pulmonary disease; $O P C A B$, off-pump coronary artery bypass grafting; $P V D$, peripheral vascular disease; $R C A$, right coronary artery. ${ }^{*}$ Critical preoperative state includes any of the following: ventricular tachycardia or fibrillation, aborted sudden cardiac death, preoperative cardiac massage, preoperative ventilation before arrival in the anesthetic room, preoperative inotropic support, intra-aortic balloon counterpulsation, and preoperative acute renal failure (anuria or oliguria $[<10$ $\mathrm{mL} / \mathrm{h}])$. 
TABLE 2. Patient characteristics and sternal infection $(\mathbf{N}=30)$

\begin{tabular}{|c|c|c|c|c|c|c|c|}
\hline \multirow[b]{2}{*}{ Risk factor } & \multicolumn{2}{|c|}{ Prevalence of risk factor } & \multicolumn{2}{|c|}{ Infection with risk factor } & \multicolumn{2}{|c|}{ Infection without risk factor } & \multirow[b]{2}{*}{$P$ valu } \\
\hline & $\mathbf{N}$ & $\%$ & $\mathbf{N}$ & $\%$ & $\mathbf{N}$ & $\%$ & \\
\hline Age $<65$ y & 338 & 42.2 & 11 & 3.3 & 19 & 4.1 & .754 \\
\hline Age $65-74$ y & 322 & 42 & 14 & 4.3 & 16 & 3.3 & .754 \\
\hline Age $\geq 75$ y & 141 & 17.6 & 5 & 3.5 & 25 & 3.8 & .756 \\
\hline Female & 200 & 25 & 13 & 6.5 & 17 & 2.8 & .031 \\
\hline Type 1 diabetes & 69 & 8.6 & 5 & 7.2 & 25 & 3.4 & .107 \\
\hline COPD & 39 & 4.9 & 5 & 12.8 & 25 & 3.3 & .009 \\
\hline Congestive heart failure & 205 & 25.6 & 12 & 5.9 & 18 & 3.0 & .103 \\
\hline Chronic renal failure & 68 & 8.5 & 6 & 8.8 & 24 & 3.3 & .049 \\
\hline PVD & 202 & 25.2 & 14 & 6.9 & 16 & 2.7 & .011 \\
\hline RCA revascularization & 489 & 61 & 19 & 3.9 & 11 & 3.5 & .794 \\
\hline Hypertension & 508 & 63 & 21 & 4.1 & 9 & 3.1 & .569 \\
\hline Hyperlipidemia & 495 & 62 & 16 & 3.2 & 14 & 4.6 & .435 \\
\hline Acute myocardial infarction $(\leq 1 \mathrm{wk})$ & 140 & 17.4 & 5 & 3.6 & 25 & 3.8 & .905 \\
\hline Intra-aortic balloon pump & 41 & 5.1 & 2 & 4.9 & 28 & 3.7 & .462 \\
\hline Old myocardial infarction ( $>3 \mathrm{wk})$ & 334 & 41.7 & 15 & 4.5 & 15 & 3.2 & .452 \\
\hline Unstable angina pectoris & 454 & 56.7 & 18 & 4.0 & 12 & 3.5 & .852 \\
\hline Left main disease & 209 & 26 & 10 & 4.8 & 20 & 3.4 & .648 \\
\hline Ejection fraction $<30 \%$ & 60 & 7.5 & 3 & 5 & 27 & 3.6 & .393 \\
\hline Critical preoperative state* & 59 & 7.4 & 2 & 3.4 & 28 & 3.8 & .617 \\
\hline Emergency operation & 71 & 8.9 & 5 & 7 & 25 & 3.4 & .228 \\
\hline Reoperation & 18 & 2.2 & 4 & 22 & 26 & 3.3 & $<.001$ \\
\hline Triple-vessel disease & 644 & 80.4 & 29 & 4.5 & 1 & 0.6 & .011 \\
\hline Composite $\mathrm{T}$ graft & 454 & 56.7 & 20 & 4.4 & 10 & 2.9 & .349 \\
\hline OPCAB & 232 & 29 & 5 & 2.2 & 25 & 4.4 & .191 \\
\hline Bypass grafts $(\geq 3)$ & 581 & 72.5 & 21 & 3.6 & 9 & 4.1 & .751 \\
\hline Obesity (BMI $\geq 30 \mathrm{~kg} / \mathrm{m}^{2}$ ) & 122 & 15.2 & 10 & 8.2 & 20 & 3.0 & .012 \\
\hline Early period & 320 & 40 & 20 & 6.3 & 10 & 2.1 & .002 \\
\hline
\end{tabular}

$B M I$, Body mass index; $C O P D$, chronic obstructive pulmonary disease; $O P C A B$, off-pump coronary artery bypass grafting; $P V D$, peripheral vascular disease; $R C A$, right coronary artery. ${ }^{*}$ Critical preoperative state includes any of the following: ventricular tachycardia or fibrillation, aborted sudden death, preoperative cardiac massage, preoperative ventilation before arrival in the anesthetic room, preoperative inotropic support, intra-aortic balloon counterpulsation, and preoperative acute renal failure (anuria or oliguria $[<10$ $\mathrm{mL} / \mathrm{h}])$.

obstructive pulmonary disease (COPD; OR, 4.477; 95\% CI, 1.450-13.820; $P<.001$ ), PVD (OR, 2.836; 95\% CI, $1.301-6.182 ; P=.009)$, obesity (OR, 2.977; 95\% CI, 1.273-6.964; $P=.012)$, and female sex (OR, 2.589; $95 \%$ CI, 1.159-5.650; $P=.020$ ).

On the basis of early analysis of our sternal infection in patients with diabetes undergoing CABG with BITA grafts, ${ }^{19}$ the use of this surgical technique in the later period of our study (2000-2006) was more selective. There was a significant decrease in the prevalence of COPD $(6.9 \%$ vs $3.5 \% ; P=.031)$ and female sex $(29.4 \%$ vs $22 \%$; $P=.023$ ). More patients in the later period underwent BITA grafting incorporating the OPCAB technique (44.3\% vs $5.95 \%$ in the early period; $P=.001)$.

When the factor of early operative period (1996-1999) was included in the regression, it was found to be independently associated with an increased incidence of sternal infection (OR, 3.115; 95\% CI, 1.370-7.092), forcing out COPD and female sex.

Mean follow-up was $8.4 \pm 4$ years. The Kaplan-Meier 10 -year survivals for patients younger than 65 years,
65-74 years old, and at least 75 years old were $75 \%$, $59 \%$, and $39 \%$, respectively $(P<.001)$. They were slightly but significantly lower than the corresponding expected survivals of the general Israeli population without operation (Figure 1). When associated comorbidities were included in calculation of expected survival, however, KaplanMeier 10-year survivals were better than the corresponding CCI-predicted survivals $(36 \%, 10 \%$, and $3 \%$ respectively; $P<.001$ for all age groups; Figure 1).

Multivariable (Cox model) predictors of decreased survival were age (HR, 1.049; 95\% CI, 1.035-1.063; $P<.001$; Figure 2), congestive heart failure (HR, 2.259; 95\% CI, 1.636-2.593; $P<.001$ ), and PVD (HR, 1.775; 95\% CI, 1.401-2.249; $P<.001)$. OPCAB was independently associated with better survival (HR, 0.636; 95\% CI, 0.472-0.859; $P=.003$; Figure 3). To assess whether the CCI formulation was indeed associated with survival in our group of patients, we fitted a Cox regression model for survival with age and the calculated CCI as covariates. Both age and CCI turned out to be independent predictors of survival $(P<.001)$. 


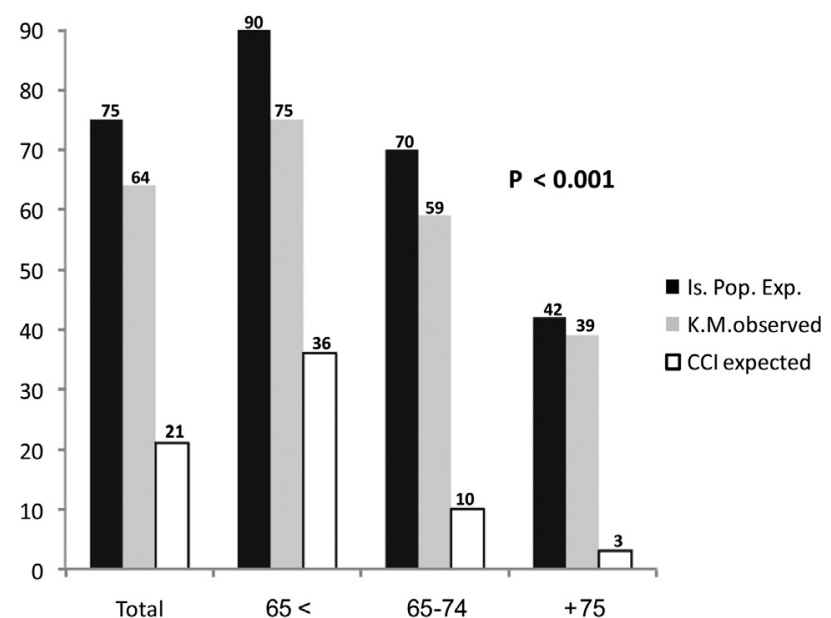

FIGURE. 1. Charlson comorbidity index-predicted 10-year survival (CCI expected) versus Israeli population expected 10-year survival (Is. Pop. Exp.) without operation and observed Kaplan-Meier 10-year survival (K.M. observed) by age groups. $P<.001$ for all pairwise comparisons of each age group. Ages are in years.

When forced into the Cox model, the operative period did not have any independent effect on survival.

\section{DISCUSSION}

The long-term success of CABG is directly related to graft patency. ITA grafts, because of their resistance to atherosclerosis, have better long-term patency then SVGs, and this patency of ITA grafts is believed to be responsible for the increased survival and decreased recurrence of angina and need for reoperation when they are used to bypass the left anterior descending coronary artery. ${ }^{5}$

Use of a single ITA graft in CABG has also been recognized as an independent predictor of improved survival in

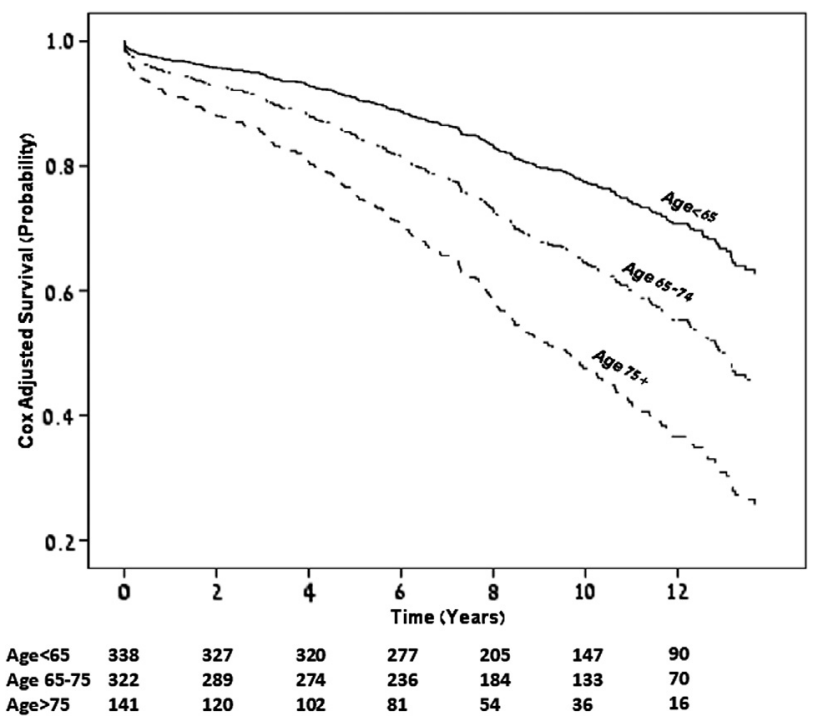

FIGURE 2. Cox-adjusted survival by age group. Ages are in years.

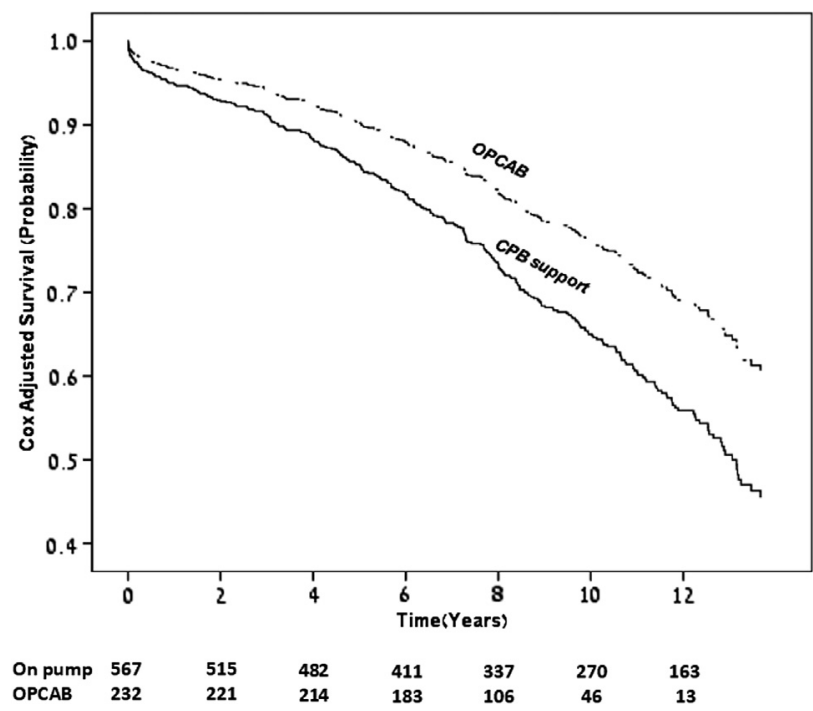

FIGURE 3. Long-term adjusted survival (Cox) by operative technique (off bypass $[O P C A B]$ vs with bypass $[C P B]$ ).

patients with diabetes. ${ }^{6,20}$ In the general population, leftsided BITA grafts are associated with improved survival, event-free survival, and freedom from repeat revascularization relative to single ITA grafts and $\mathrm{SVGs}^{7}$; however, the application of BITA grafting technique in patients with diabetes is controversial because its effect on long-term survival is questionable as a result of the increased risk of sternal dehiscence and sternal infection ${ }^{8}$ caused by the more extensive devascularization associated with harvesting 2 ITAs $^{21}$ and in view of the excellent survival benefit obtained with a single ITA graft.

Increased risk of sternal complication was also reported in the subset of patients with diabetes in our previous publication describing routine use of BITA grafts in a cohort of 1515 patients who underwent CABG with skeletonized BITA grafts in our center between 1996 and 2001. ${ }^{10}$ The overall risk of sternal complication in this cohort was $1.9 \%$; however, occurrences of sternal complications (deep infection and dehiscence) in the patients with type 2 and type 1 diabetes were significantly higher than in patients without diabetes $(2.9 \%$, and $5.9 \%$, respectively, vs $0.8 \%$ ). Type 2 diabetes (OR, 4.64; 95\% CI, 1.85-11.59) and type 1 diabetes (OR, 6.9; 95\% CI, 1.35-35.27) were also found to be independent predictors of sternal complications.

A larger cohort of patients with diabetes with longer follow-up is described in this report. Despite increased occurrence of sternal complications in this report (3.4\% in the type 2 subset and $7.2 \%$ in the type 1 subset), the observed hospital mortality $(2.9 \%)$ was significantly lower than the EuroSCORE-calculated mortality $(7.0 \% ; P<.001)$.

Moreover, the actual 10-year survivals (Kaplan-Meier) as well as risk adjusted (Cox) survival estimates are 
significantly better than the corresponding calculated CCIpredicted 10-year survivals for all age groups $(<65,65-74$, and $\geq 75$ years), suggesting significant survival benefit of BITA grafts for all age groups despite the increased risk of sternal complications.

The CCI is a well-validated tool that divides patients according to comorbidity severity, which is translated to survival. It is influenced by several preoperative variables such as age, cerebrovascular disease, pulmonary disease, congestive heart failure, myocardial infarction, PVD, diabetes, renal dysfunction, and several other conditions that are much rarer and probably less relevant to our study (such as malignancy). ${ }^{13}$ The unfavorable predicted survival without surgery and the improved survival with surgery in this study are not surprising. There is a major effect of heart disease on survival. Schmidt and coworkers, ${ }^{13}$ in a recent nationwide population study of all hospitals in Denmark, analyzed 234,331 patients with first-time acute myocardial infarction and found that even in the current era, those who survive 30 days have a $6 \%$ risk of dying during the first year even if no comorbidity exists. If the CCI score is greater, then the risk of dying during the first year increases to $31 \%$. (The patients in our study had a mean CCI of 5.)

In an effort to reduce the risk of sternal complications, we analyzed our early results and became more careful in the later period with regard to patient selection for BITA grafts, with especial attention to the risk factors of diabetes, COPD, reoperation, female sex, and obesity. ${ }^{10,19}$ The decreased occurrence of sternal complications in the later period (2000-2006) may be related to decreased prevalences of COPD, obesity, and female sex in that period.

The more liberal use of BITA grafts in patients with type 1 diabetes in the later period was based on Lev-Ran and colleagues' report. ${ }^{22}$ In that study, occurrence of sternal complications among patients with type 1 diabetes with BITA was similar to that of patients with type 1 diabetes treated with single ITA ( $4 \%$ vs $2.7 \% ; P>.999)$ This policy cannot be supported by results of our study. Occurrence of $7.2 \%$ sternal complications in the subset of patients with type 1 diabetes cannot be acceptable.

In another study by Lev-Ran and colleagues, ${ }^{23}$ similar early outcomes, including similar incidence of sternal infection, were observed in patients with type 2 diabetes treated with BITA and single ITA (1.8\% in both groups). During follow-up (4-7.5 years), there were fewer repeated revascularizations $(4.4 \%$ vs $12.3 \% ; P=.025)$ and major adverse events $(11.2 \%$ vs $36.8 \% ; P<.001)$ in the BITA group. At 7 years, Kaplan- Meier survival $(75 \%$ vs $59 \%$, $P=.006)$ and freedom from cardiac-related mortality ( $92 \%$ vs $68 \% ; P<.001)$ were superior in the BITA group. The survival benefit observed in our study, together with results of Lev-Ran and colleagues' study, ${ }^{23}$ support the use of
BITA grafts in patients with type 2 diabetes of all age groups.

The survival benefit observed in our report and the superiority of BITA observed in Lev-Ran and colleagues' report $^{23}$ negate results of previous study comparing large groups of matched patients with diabetes receiving BITA grafts versus single ITA grafts. This study suggests 5-year survival benefit of BITA grafts relative to single ITA grafts only in the subgroups of patients between 60 and 69 years of age, whereas single ITA grafts were beneficial for patients older than 79 years. ${ }^{24}$

An interesting finding of our study was the better longterm survival of patients with diabetes undergoing CABG with BITA grafts without extracorporeal circulation (OP$\mathrm{CAB}$ ). In our report, the use of OPCAB was an independent predictor of better long-term survival in patients with diabetes undergoing CABG with BITA grafts. This was a relatively large cohort (232 patients) of patients with diabetes undergoing OPCAB with BITA grafts and is the first to show a survival advantage for this surgical technique in patients with diabetes. A previous study describing the superiority of $\mathrm{OPCAB}$ in patients with diabetes reported only early outcomes relative to outcomes of patients operated on with cardiopulmonary bypass. ${ }^{25}$ In that study, the better outcome of patients undergoing OPCAB was attributed to the more common use of arterial conduits. This explanation is not pertinent to our report, because all patients in our study underwent left-sided arterial grafting with two ITAs. A possible explanation for the better survival of patients undergoing OPCAB might be the routine use of clopidogrel bisulfate (INN clopidogrel) treatment after OPCAB procedures. The recommended duration of postoperative clopidogrel treatment was only 3 to 6 months, however, and we do not have complete data on the actual duration and adherence of patients to this antiplatelet treatment.

In conclusion, our study suggests that the survival benefit of BITA grafts for patients with diabetes outweighs the early adverse effect of sternal wound complications. Occurrence of these complications can be reduced by selective use of BITA grafts in this subset of patients. The study did not compare long-term results with those of single ITA grafts; however, its results suggest that to reduce occurrence of sternal complications, this technique should not be applied to patients with COPD, PVD, reoperations, and obesity (especially female patients). Despite our observation that type 1 diabetes was not an independent predictor of sternal complications, we do not recommend routine use of BITA grafts in patients with type 1 diabetes. Whenever possible, we advocate the use of OPCAB technique in patients with diabetes receiving BITA grafts. Age is not a contraindication for BITA graft use; however, further studies are required to compare long-term outcomes of BITA and single ITA grafts in elderly patients with diabetes. 


\section{Limitations}

This is a retrospective study, and potential long-term benefits of BITA grafts for patients with diabetes could not be demonstrated without comparing its outcome with that of CABG procedures incorporating a single ITA and other conduits, such as SVGs or radial arteries. Postoperative angiograms and coronary computed tomographic angiograms were available only in a small number of patients, mostly in symptomatic patients. Therefore, they could not be included in this report.

\section{References}

1. Haffner SM, Lehto S, Rönnemaa T, Pyörälä K, Laakso M. Mortality from coronary heart disease in subjects with type 2 diabetes and in nondiabetic subjects with and without prior myocardial infarction. N Engl J Med. 1998;339:229-34.

2. ElBardissi AW, Aranki SF, Sheng S, O'Brien SM, Greenberg CC, Gammie JS Trends in isolated coronary artery bypass grafting: an analysis of the Society of Thoracic Surgeons adult cardiac surgery database. J Thorac Cardiovasc Surg. 2012;143:273-81.

3. Smith SC Jr, Faxon D, Cascio W, Schaff H, Gardner T, Jacobs A, et al. Prevention Conference VI: Diabetes And Cardiovascular Disease. Writing Group VI: revascularization in diabetic patients. Circulation. 2002;105: e165-9.

4. Lytle BW, Loop FD, Cosgrove DM, Ratliff NB, Easley K, Taylor PC. Long-term ( 5 to 12 years) serial studies of internal mammary artery and saphenous vein coronary bypass grafts. J Thorac Cardiovasc Surg. 1985;89:248-58.

5. Loop FD, Lytle BW, Cosgrove DM, Stewart RW, Goormastic M, Williams GW, et al. Influence of internal-mammary-artery graft on 10 year-survival and other cardiac events. N Engl J Med. 1986;314:1-6.

6. Holmes DR Jr, Kim LJ, Brooks MM, Kip KE, Schaff HV, Detre KM, et al. The effect of coronary artery bypass grafting on specific causes of long-term mortality in the Bypass Angioplasty Revascularization Investigation. J Thorac Cardiovasc Surg. 2007; 134:38-46.

7. Taggart DP, D'Amico R, Altman DG. Effect of arterial revascularization on survival: a systematic review of studies comparing bilateral and single internal mammary arteries. Lancet. 2001;358:870-5.

8. Paul M, Raz A, Leibovici L, Madar H, Holinger R, Rubinovitch B. Sternal wound infection after coronary artery bypass graft surgery: validation of existing risk scores. J Thorac Cardiovasc Surg. 2007;133:397-403.

9. Peterson MD, Borger MA, Rao V, Peniston CM, Feindel CM. Skeletonization of bilateral internal thoracic artery grafts lowers the risk of sternal infection in patients with diabetes. J Thorac Cardiovasc Surg. 2003;126:1314-9.

10. Pevni D, Uretzky G, Mohr A, Braunstein R, Kramer A, Paz Y, et al. Routine use of bilateral skeletonized internal thoracic artery grafting: long-term results. Circulation. 2008;118:705-12.
11. West NE, Ruvgrok PN, Disco CM, Webster MW, Lindeboom WK, O'Neill WW, et al. Clinical and angiographic predictors of restenosis after stent deployment in diabetic patients. Circulation. 2004;109:867-73.

12. Roques F, Michel P, Goldstone AR, Nashef SA. The logistic EuroSCORE. Eur Heart J. 2003;24:881-2.

13. Schmidt M, Jacobsen JB, Lash TL, Bøtker HE, Sørensen HT. 25-year trend in first-time hospitalization for acute myocardial infarction, subsequent short and long term mortality, and the prognostic impact of sex and comorbidity: a Danish nationwide cohort study. BMJ. 2012;344:e356.

14. Israel Central Bureau of Statistics. Complete life tables of Israel, 2005-2009. Publication No. 1450. Available at: http://www1.cbs.gov.il/webpub/pub/text_ page_eng.html?publ $=35 \&$ CYear $=2010 \& C M o n t h=1$. Accessed June 2011.

15. Pevni D, Mohr R, Lev-Ran O, Paz Y, Kramer A, Frolkis I, et al. Technical aspects of composite arterial grafting with double skeletonized internal thoracic arteries. Chest. 2003;123:1348-54.

16. Sabik JF 3rd, Blackstone EH. Coronary artery bypass graft patency and competitive flow. J Am Coll Cardiol. 2008;51:126-8.

17. Radford MJ, Arnold JM, Bennett SJ, Cinquegrani MP, Cleland JG, Havranek EP, et al. ACC/AHA key data elements and definitions for measuring the clinical management and outcomes of patients with chronic heart failure: a report of the American College of Cardiology/American Heart Association Task Force on Clinical Data Standards (Writing Committee to Develop Heart Failure Clinical Data Standards): developed in collaboration with the American College of Chest Physicians and the International Society for Heart and Lung transplantation: endorsed by the Heart Failure Society of America. Circulation. 2005;112:1888-916.

18. Clark RE. The STS Cardiac Surgery National Database: an update. Ann Thorac Surg. 1995;59:1376-80; discussion 1380-1.

19. Matsa M, Paz Y, Gurevitch J, Shapira I, Kramer A, Pevny D, et al. Bilateral skeletonized internal thoracic artery grafts in patients with diabetes mellitus. J Thorac Cardiovasc Surg. 2001;121:668-74.

20. Hirotani T, Kameda T, Kumamoto T, Shirota S, Yamano M. Effects of coronary artery bypass grafting using internal mammary arteries for diabetic patients. JAm Coll Cardiol. 1999;34:532-8.

21. Carrier M, Grégoire J, Tronc F, Cartier R, Leclerc Y, Pelletier LC. Effect of internal mammary artery dissection on sternal vascularization. Ann Thorac Surg. 1992;53:115-9.

22. Lev-Ran O, Mohr R, Amir K, Matsa M, Nesher N, Locker C, et al. Bilateral internal thoracic artery grafting in insulin-treated diabetics: should it be avoided? Ann Thorac Surg. 2003;75:1872-7.

23. Lev-Ran O, Braunstein R, Nesher N, Ben-Gal Y, Bolotin G, Uretzky G. Bilateral versus single internal thoracic artery grafting in oral treated diabetic subsets: comparative seven-year outcome analysis. Ann Thorac Surg. 2004;77:2039-45.

24. Toumpoulis IK, Anagnostopoulos CE, Balaram S, Swistel DG, Ashton RC Jr, DeRose JJ Jr. Does bilateral internal thoracic artery grafting increase longterm survival of diabetic patients? Ann Thorac Surg. 2006;81:599-606; discussion 606-7.

25. Emmert MY, Salzberg SP, Seifert B, Rodriguez H, Plass A, Hoerstrup SP, et al. Is off-pump superior to conventional coronary artery bypass grafting in diabetic patients with multi-vessel disease? Eur J Cardiothorac Surg. 2011;40:233-9. 